\title{
Derleme
}

Mersin Univ Saglık Bilim Derg 2019;12(1):126-135

doi: $10.26559 /$ mersinsbd.513300

\section{Diffüz lamellar kretatit: Tanı ve tedavi yöntemleri Cüneyt Karaarslan}

Göz Hastalıkları Uzman Doktor, Dünyagöz Adana Hastanesi

Öz

Refraktif cerrahi sonrası gelişen diffüz lameller keratit, çoğunlukla unilateral (tek gözde), görme ekseninden uzak, periferal yerleşimli küçük gri-beyaz korneal noktacıklar şeklinde ortaya çıan bir komplikasyon tablosudur. Başlangıç evrelerde farkına varılmaz ve uygun tedavi ile önlem alınmazsa, ileride ciddi görme kaybına neden olabilmektedir. Özellikle aktif ve genç nüfusun, gözlük ve lens bağımlılığından kurtulmak için tercih ettiği refraktif cerrahi gün geçtikçe daha yoğun bir şekilde uygulanmaktadır. $\mathrm{Bu}$ yazıda; ilerleyici ve geri dönüşümsüz kornea ve görme hasarına neden olabilecek, diffüz lameller keratitin, erken tanısı ve tedavisi ile ileride gelişebilecek kalıcı görme kaybının önlenmesi için güncel yaklaşımların ortaya konulması amaçlanmıştır.

Anahtar sözcükler : Refraktif cerrahi, diffüz lameller kerattit, korneanın kalıcı nekrozu

\section{Diffuse lamella keratitis: diagnosis and treatment methods}

\begin{abstract}
Developing after refractive surgery, Diffuse Lamellar Keratitis is a complication that appears as small gray-white corneal spots in the periphery. It is mostly unilateral (one-eye) and distant to the visual axis. If it goes unnoticed at initial stages, and if appropriate treatment is not applied, it may cause severe visual impairment. Refractive surgery is especially preferred by active and young population to be released of glasses and lens dependence, and is becoming widely applied with each passing day. In this paper, the purpose is to determine the early diagnosis and treatment modalities for Diffuse Lamellar Keratitis, and to examine current approaches for the prevention of permanent visual impairment, which may lead to progressive and irreversible corneal and visual damage.
\end{abstract}

Keywords: Refractive surgery, diffuse lamellar keratitis, visual impairment

Yazının geliş tarihi: 16.01.2019 Yazının kabul tarihi: 18.02.2019

Sorumlu Yazar: Uzm.Dr. Cüneyt Karaarslan, Dünyagöz Adana Hastanesi Başhekimi, Tlf : 0533373 72 73, e-posta : cuneyt.karaarslan@dunyagoz.com 


\section{Giriş}

Kornea gözün en öndeki ve en önemli refraktif anatomik oluşumudur. Saydamdır ve bu saydamlık görmenin temel unsurudur. Kornea bu saydamlığını bir dizi özelleşmiş hücre ve bu hücrelerin karmaşık ilişki ve iletişimleri ile korur. Bu ilişki ve iletişim ağ herhangi bir yerde ve herhangi bir nedenle kesinti ya da zarara uğrayacak olursa korneal saydamlık bozulabilir ve gelişen bu opaklık gittikçe genişleyip skarlaşabilir. ${ }^{1}$

Daha önceleri gözün travma veya enfeksiyonları gibi nedenlerle ortaya çıkan bu keratopatik durum günümüzde daha çok refraktif korneal lazer cerrahisine bağlı olarak gelişebilmektedir. Özellikle ara yüzey oluşumuna neden olan I-LASIK, LASIK ve SMILE gibi refraktif işlemlerin ilk günlerinde oluşturulan ara yüzeyin periferik bölümünde korneada bașlayan bu inflamatuar yanıt ilk kez 1998'de "Sands of Sahara" olarak adlandırılmıștır. ${ }^{2}$ Ancak, günümüzde daha yaygın klinik adlandırılması diffüz lamellar keratitlerdir. ${ }^{3}$

Refraktif korneal lazer cerrahisi de kornea yüzeyindeki sinir ağını ya da korneal hücreler arası iletişim ağını kesintiye uğratarak ya da bu alana yabancı hücre girișine neden olarak (flep arası beyaz-kırmızı kan hücresi gibi) granülasyon, ödem ve inflamasyona neden olabilir. Oluşan bu temel reaksiyonlar bir başka tetikçi ko-faktör (kimyasal, bedensel, çevresel olabilir) ile aşırı duyarlılık reaksiyonuna dönüşüp bir çeşit otoimmün yanıt ile ileri doku hasarına yol açabilir.4

Günlük yaşamın giderek hızlanması, insanlarda daha net ve araçsız görme ihtiyacını artırmış ve cerrahi çözümlere yöneltmiştir. Özellikle aktif, genç yaştaki refraksiyon kusuru olan hastalarda, kısa sürede mükemmel bir görme netliği sağlayan, retraktif cerrahi gidererek daha siklıkta tercih edilmeye başlanmıștır. ${ }^{5}$ Ancak ilerleyen teknolojilere karșın retraktif cerrahi sonrasında, körlüğe varabilen bazl komplikasyonlar gelişebilmektedir. $\mathrm{Bu}$ komplikasyonlardan birisi de diffüz lameller keratitlerdir (DLK). ${ }^{6}$
DLK, non-enfeksiyöz, flep-stroma arası korneal ara yüzey yerleşimli, beyaz kan hücreleri ve inflamatuar hücrelerden köken alan başlangıçta periferik ve ilerledikçe kornea merkezini de etkisi altına alan steril bir inflamasyondur. ${ }^{7}$

$\mathrm{Bu}$ yazıda, refraktif lazer cerrahisinden sonra erken dönemde ortaya çıkan, nadir ancak sonuçları açısında çok önemli olan DLK'lerin; erken tanısı, evreleri ve kalıcı görme kaybının önlenmesi için her aşamada nasıl tedavi edilmesi gerektiği irdelenmektedir. Ayrıca giderek daha sıklıkta uygulanan cerrahi tedavi sonrasında bu komplikasyona dikkat çekilmesi ve korunma önlemlerinin neler olabileceği konusu incelenmektedir.

\section{Görülme sıklığı ve nedenleri}

DLK özellikle refraktif lazer cerrahisi sonrası 1-5. günde görülür. Yapılan çalışmalarda görülme sıklığı \%0.6-0.81 olarak bildirilmektedir. ${ }^{8}$ Türkiye'de cerrahi sonrası DLK sıklığı konusunda bir çalışmaya ulaşılamadı. Literatürde çok daha geç dönemde ortaya çıkan (post-op. 4-10 yıl) DLK olguları da rapor edilmiștir. Ancak cerrahiden bu kadar uzun süre geçtikten sonra ortaya çıkan DLK olgularında mutlaka şiddetli viral konjonktivitler, travma, göziçi cerrahi gibi ek bir sebebin olabileceği de unutulmamalıdır. ${ }^{9}$ Gelişen non-spesifik inflamasyon sıklıkla intraoperatif korneal epitelyal defektle birlikte ve onunla da ilişkilidir. ${ }^{10}$

Cerrahi sırasında kullanılan eldiven pudrası, sponge ya da marking pen boyasina ait kimyasal debrisler veya povidon iodin DLK'ya neden olabilir.11 Postoperatif dönemde uygulanan bazı antibiyotikli veya suni gözyaşı içeren göz damlaları da DLK'ya yol açabilir.12 Bunlar dişında hastaya ait endojen nedenler de bulunmaktadır. Bunlar içinde; atopik yapı, geniş göz kapağı palpebral fissürü, meibomian bez disfonksiyonları ve düşük korneal endotelyal kapasite sayllabilir. ${ }^{13}$ Şekil 1'de DLK'lere neden olan tüm faktörler şematik halde sunulmuştur. 


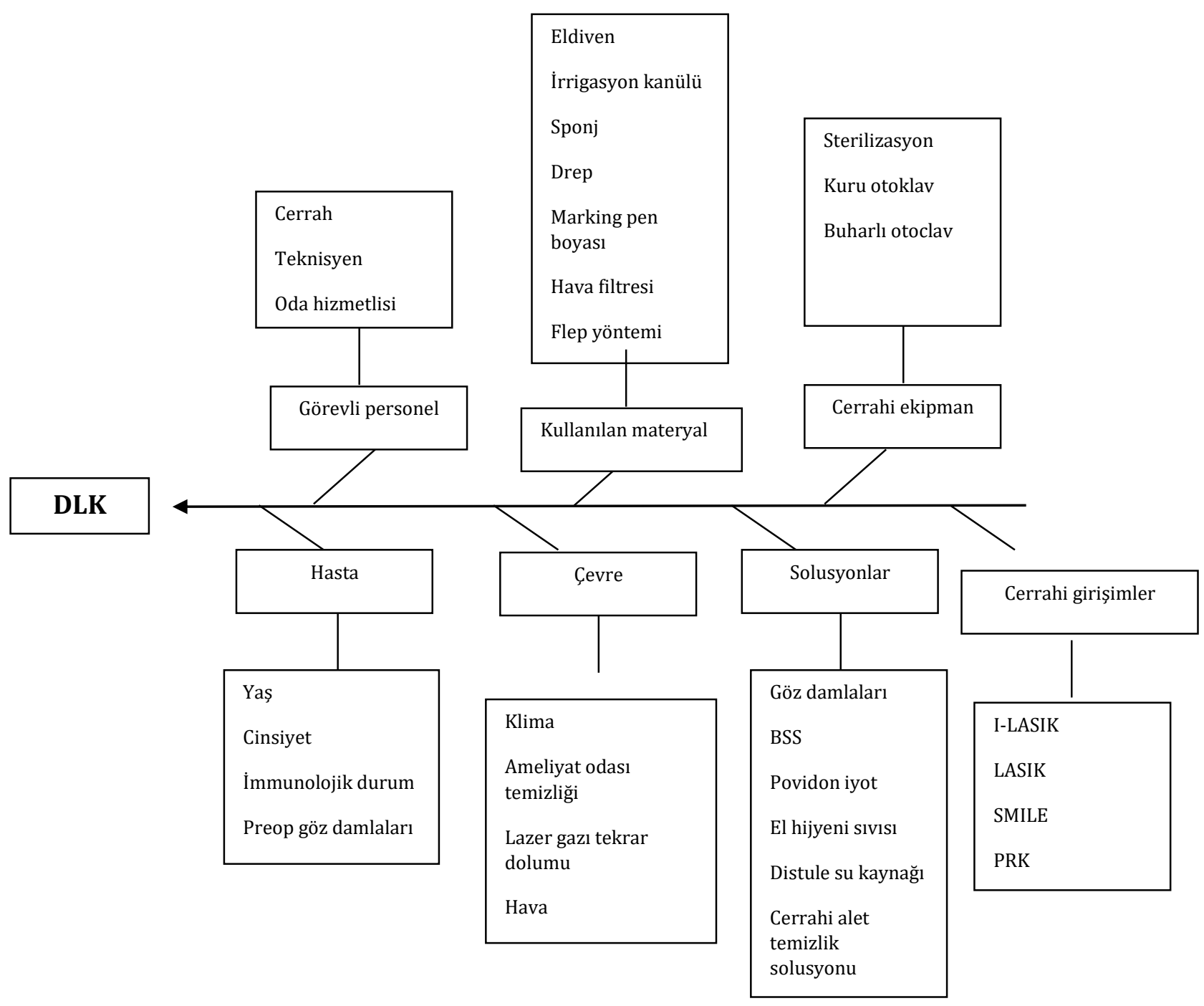

Şekil 1: DLK gelişimine etki eden faktörler ${ }^{14}$

Uygulanan cerrahi işlemin nasıl yapıldığı, cerrahın becerisi, oluşturulan doku hasarının şiddeti, flep ara yüzeyine hemoraji ve hangi ameliyat yöntemi olduğu da DLK gelişiminde önemli bir etkiye sahiptir. DLK en sık I-LASIK ve LASIK daha sonra da SMILE ve PRK cerrahi yöntemleri sonrası görülmektedir. ${ }^{15}$ Özellikle LASIK sonrası görülen DLK oranı femtosaniye ile oluşturulan flep ara yüzeyinde (\%0.4-19.4), mikrokeratom ile oluşturulan fleplerdekilere (\%0.4-7.7) göre çok daha sıktır. Ayrıca yine femtosaniye lazer ile oluşturulan fleplerde, geniş çap ve kullanılan enerjinin yüksek olması da DLK gelişme olasılığını artırıcı faktörlerdir. ${ }^{16}$

\section{Kliniği ve gelişim evreleri}

Bir hastada Postoperatif özellikle 2. günden itibaren özellikle tek gözde irritasyon, yabancı cisim hissi, bulanık görme, ağrı ve ışık hassasiyeti varsa DLK'den mutlaka şüphelenmek ve hastayı ona göre muayene ve takip etmek gerekir. ${ }^{17}$

DLK'in dört klinik evresi vardır ve birinci evresi iç içe iki alt evreden oluşmaktadır. 
- $\quad$ Evre 1a: Refraktif cerrahi sonrası ikinci günde flep dayanak yerinde de veya flep kenarında silik granüler infiltrat oluşumu,

- Evre 1b: Flep dayanak yerinde veya flep kenarında sentripetal (periferden merkeze doğru) gelişen ve artan daha belirgin infiltrat oluşumu,

- Evre 2: Refraktif cerrahi sonrası üçüncü, dördüncü günde artık infiltratlar merkezde kümelenmeye ve yoğun, beyazlıklar olarak görme

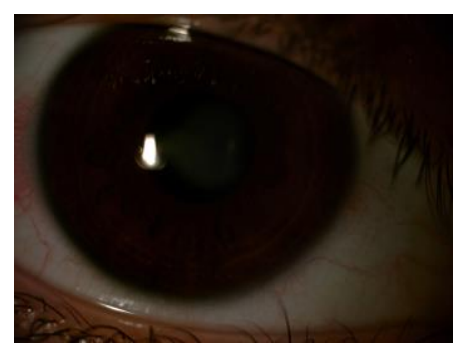

Resim 1. Santral korneal opasifikasyon

\section{Ayırıcı tanı}

Hastada DLK tanısı düşünülüyorsa ayırıcı tanısının da dikkatle yapılması gerekmektedir. DLK klinik çalışmalarda en çok CTK (Santral toksik keratopati), Santral toksik keratopati, PISK (Artmış göziçi basıncına bağlı stromal keratopati), EK (Enfeksiyöz keratit) ve EI (Epitelyal büyüme) ile karıştırılabilir (Tablo 1). ${ }^{19}$

DLK günlük pratikte en çok santral toksik keratopati (CTK) ile karıştırılabilir. CTK refraktif lazer cerrahisinden sonra hızla fakat DLK'den farklı olarak doğrudan görme eksenini etkileyecek şekilde kornea merkezinde görülür. Tedavisinde kortikosteroidler hiçbir şekilde önerilmez ve flep lifting ile irrigasyonun pek yararı yoktur. ${ }^{20}$ eksenini de etkilemeye başlaması,

- $\quad$ Evre 3: Merkezdeki, granüler beyazlık yoğunluğunun koyulaşması, inflamasyon artışı ve stromal skarlaşma nedeniyle görme ekseninin kapanmaya başlaması,

- Evre 4: Korneada merkezinde ciddi inflamasyon, stromal nekroz, erime ve kalıcı skar nedeniyle ciddi görme kaybı oluşması. ${ }^{18}$

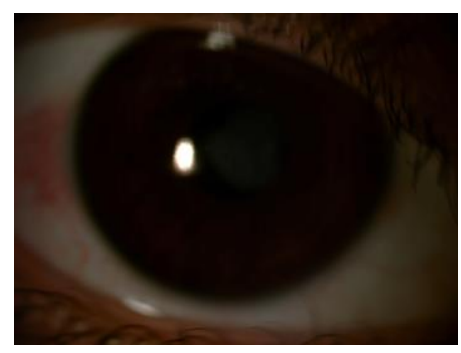

Resim 2. Tedavi sonrası DLK

PISK artmış göz içi basıncı ile gelişen bir stromal keratopatidir. DLK'in tersine kortikosteroidle tedavi edilemez çünkü başlıca nedeni postop aşırı kortizon kullanımıdır ve ortaya çılkma süresi DLK'e göre daha geç bir dönemde görülür üstelik gelişimi daha yavaştır. ${ }^{21}$

Enfeksiyöz keratitler ve endotelyal ingrowth da DLK ile daha nadiren de olsa karışabilir yerleşim ve ortaya çıkış şekilleri ile tedavileri oldukça değişiktir. ${ }^{22}$

Görüldüğü üzere DLK'in doğru tanısı ve ayırıcı tanısı için postop 1.-2. gün kontrolü çok büyük önem taşır ki ileri evrelerdeki kalıcı doku hasarı ve görme kaybı gelişmesinin önüne geçilebilir. 
Tablo 1. DLK'in ayırıcı tanısı ve karşılaştırılacak klinik özellikler²3

\begin{tabular}{|c|c|c|c|c|c|}
\hline Klinik özellikler & $\begin{array}{l}\text { DLK (Diffüz } \\
\text { lameller } \\
\text { keratit) }\end{array}$ & $\begin{array}{l}\text { CTK (Santral } \\
\text { toksik } \\
\text { keratopati) }\end{array}$ & $\begin{array}{l}\text { PISK (Artmış } \\
\text { göziçi } \\
\text { basıncına } \\
\text { bağlı stromal } \\
\text { keratopati) }\end{array}$ & $\begin{array}{l}\text { EK } \\
\text { (Enfeksiyöz } \\
\text { keratit) }\end{array}$ & $\begin{array}{l}\text { EI (Epitelyal } \\
\text { büyüme) }\end{array}$ \\
\hline Etiyoloji & İnflamatuar & Toksik & Sıvı birikimi & $\begin{array}{l}\text { Bakteri } \\
\text { Mikobakteri } \\
\text { Mantar }\end{array}$ & $\begin{array}{l}\text { Ara yüzeyde } \\
\text { epitel } \\
\text { hücreleri }\end{array}$ \\
\hline Ortaya çıkış & 1-5 gün & 2-7gün & 10-21gün & 3-21gün & $\begin{array}{l}14 \text { gün veya } \\
\text { daha sonrası }\end{array}$ \\
\hline $\begin{array}{l}\text { Başlangıçta } \\
\text { görmeye etkisi }\end{array}$ & Minimal & Belirgin & Belirgin & Değişken & Minimal \\
\hline Ăgrı & $\begin{array}{l}\text { Yabancl } \\
\text { cisim hissi }\end{array}$ & Yok & Minimal & Orta & Yok \\
\hline Yerleşim & Yaygın & $\begin{array}{l}\text { Fokal, keskin } \\
\text { sinırlı }\end{array}$ & Yaygın & $\begin{array}{l}\text { Fokal, } \\
\text { sinırları } \\
\text { belirsiz }\end{array}$ & $\begin{array}{l}\text { Flep } \\
\text { kenarında }\end{array}$ \\
\hline Haze & $\begin{array}{l}\text { 4. evreye } \\
\text { kadar } \\
\text { granüler }\end{array}$ & $\begin{array}{l}\text { Merkezi } \\
\text { yoğunluk, çevre } \\
\text { temiz }\end{array}$ & Yaygin & $\begin{array}{l}\text { Lezyonda } \\
\text { yoğun, çevre } \\
\text { temiz }\end{array}$ & $\begin{array}{l}\text { Fokal } \\
\text { hücresel }\end{array}$ \\
\hline Gözde kızarıklık & Yok & Yok & Yok & Orta-ciddi & Yok \\
\hline Göziçi basıncı & Normal & Normal & Yüksek & Normal & Normal \\
\hline $\begin{array}{l}\text { Arayüzeyde sıvı } \\
\text { birikimi }\end{array}$ & Yok & Yok & Var & Yok & Yok \\
\hline $\begin{array}{l}\text { Topikal } \\
\text { kortizona yanıt }\end{array}$ & İyi & $\mathrm{Az}$ & Kötüleşme & Değisken & Yok \\
\hline $\begin{array}{l}\text { Ağızdan } \\
\text { kortizona yanıt }\end{array}$ & Gayet iyi & Az ya da yok & Kötüleşme & Sinırlı & Yok \\
\hline $\begin{array}{l}\text { Flep lifting ve } \\
\text { irrigasyona yanıt }\end{array}$ & İyi & Zayıf & Yok & $\begin{array}{l}\text { İyi } \\
\text { Flepe bağlı }\end{array}$ & $\begin{array}{l}\text { İyi } \\
\text { Flepe sütür } \\
\text { gerekebilir }\end{array}$ \\
\hline
\end{tabular}




\section{Tedavi}

DLK'in tedavisine hangi evrede olursa olsun mutlaka zaman kaybetmeden başlamak gerekir. Evresine göre tedavisi de farklılıklar taşır. ${ }^{24}$

Tablo 2'de görüldüğü üzere DLK refraktif kornea lazer cerrahisini takip eden 12 gün içinde periferik alanda başlayıp, 1 hafta10 gün içinde merkezileșerek yoğun, beyaz ve kalıcı bir leke haline dönüşebilir. ${ }^{25}$ Aslında DLK "1a evresinde", lazer cerrahisine karșı gelişen normal bir nötrofilik inflamatuar yanıt şeklindedir. İnflamasyon bu aşamada sınırlı kalabileceği gibi bir çeşit oto-immün yanıt gibi artarak progresif doku hasarına da yol açabilmektedir. ${ }^{26} \quad 0$ yüzden burada Postoperatif hasta yakın takibi büyük önem taşır ve hatta Postoperatif 5. günden sonra hastanın görmesi iyi, korneası saydam ve şikâyeti yok ise artık DLK riski de yok demektir.27 Tablo 1'de DLK'in klinik evreleri, bu evrelerin ortaya çıkış zamanı ve evrelere göre görme memnuniyeti, korneal opasifikasyon durumu ve her bir evrede tercih edilecek tedavi yöntemi gösterilmektedir.

Dolayısı ile DLK için ekzojen ya da endojen kaynaklı erken ortaya çıkan hızla ilerleyici bir hipersensitivite reaksiyonudur demek hiç de yanlış olmayacaktır. Kaldı ki tedavisinde zaman kaybetmeden topical ve/veya sistemik kortikosteroidler ile sistemik $\mathrm{H}_{2}$ reseptör blokerlerin yani sistemik antihistaminiklerin de kullanılması esastır. ${ }^{28}$

Her ne kadar topikal ve sistemik tedavi çok önemli ise de flepi tekrar kaldırarak (flep lifting) yapılan ara yüzey yıkaması (interface irrigasyon) da özellikle 2 ve 3 . evre DLK'de şarttır. Bu mekanik ve temizleyici işlem inflamasyonun ara yüzeyden süpürülüp yıkanması gibi bir temizleyici etkiye sahiptir. ${ }^{29}$

Kalıcı korneal hasar ve stromal erime oluşmadan yapılması gereken bu tedavi girişimleri evre 4 den sonra pek işe yaramaz. $\mathrm{Bu}$ evreden sonra oluşmuş olan santral lökom PTK (fotorefraktif keratektomi) ya da daha ileri ve derin kornea nekrozu gelişmiş olgularda keratoplasti ile tedavi edilir. ${ }^{30}$

\section{Tartışma}

Diffüz lamellar keratit, kornea stroma yüzeyinde lamellar ara yüzey oluşturan, herhangi bir cerrahi prosedür sonrası ortaya çlkabilir. İlerleyici, seyrek, inflamatuar bir komplikasyondur. $\mathrm{Bu}$ süreç hangi evrede yakalanırsa o evrede durdurulmalıdır. ${ }^{31}$ Erken tanı çok önemlidir. Çünkü normal bir inflamatuar yanıt olarak başlayıp, abartılmış aşırı duyarlılık reaksiyonuna dönüşüp ciddi doku hasarı ve görme kaybı ile sonuçlanabilir. ${ }^{32}$

Yakın dönemde refraktif cerrahi geçirmiş bir hastada ikinci günden itibaren başlayan yabancı cisim hissi, görmede netlik kaybı, ağrı ve irritasyon ile gelen hastada özellikle ve öncelikle düşünülmeli şayet yeterli teknolojik imkanlar yoksa mutlaka ileri bir merkeze yönlendirilmelidir. Tecrübeli bir cerrah tarafından biyomikroskopi, otorefraktometri, refraktif muayene, kornea topografisi, pakimetrisi ve ön segment OCT si ile takibi şarttır. ${ }^{33}$

Diffüz Lameller Keratit ilk 24 saat içinde semptom vermez. Hastanın görmesi iyidir ancak 48 saate doğru hastanın bulanık görme, hafif ağrı şikâyetleri başlar, bu dönemde flep altı dikkatli incelenirse punktat yapılı, paralel dizilimli, kum görünümlü enflamasyon görülür. $\mathrm{Bu}$ evrede saat başı uygulanacak steroid ile hastanın takibi tavsiye edilmesine rağmen 48-72 saat içinde flep altı yıkamaya hazır olunmalıdır. Steroid ile düzelme eğilimi gösteren hastalarda 2 hafta süre ile tedaviye devam edilmelidir. ${ }^{34}$ 
Tablo 2. DLK'in evrelerinin başlangıç günü, görmeye etkisi, yerleşimi ve tedavisi.

Evre Gün $\begin{gathered}\text { Görme } \\ \text { bozukluğu } \\ \text { seviyesi }\end{gathered}$ Yoğunluk

Düzelme göstermeyen, ilerleyen hastalarda flep altı görüntü değişir. Nokta şeklinde ve parçalı görünen birikintiler birleşmeye başlar. Bu birleşme neticesinde ortaya çıan tablo kornea ortasında koyu beyaz alan içinde ince açlk kahve çatlaklar şeklindedir. Hızlı düzeIme için bu evre en son flep altı yıkama evresidir. Bundan sonraki dönemlerde artık iyileşme çok yavaş olacaktır. ${ }^{35}$

Son evrede artık ortada eliptik, sedef beyazı renginde bir lezyon söz konusudur. $\mathrm{Bu}$ evreye gelen hastalarda tedavi süresi artık birkaç aydır. Artık bu aşamada flep altı yıkama makrostrialara ve stromal hasar artışına neden olabiliceği için topikal ve sistemik steroid tedavisi tercih edilmelidir. ${ }^{36}$

DLK özellikle ilk evrelerde durdurulup yeterli tedavi sağlanamazsa ileride gelişebilecek sorunlar cerrah. hasta ve sağlık kuruluşu için ciddi bir maliyet artışına neden olacaktır. Bu komplikasyonun tedavisi daha geç ve güç olacak en sonunda daha pahalı ve daha riskli olan kornea nakline gereksinim duyulabilecektir. ${ }^{37}$

Gelecekte ise immünolojik sitoprotektif ajanların daha yaygın kullanımı yada korneal-limbal kök hücre katılımlı tedavilerin de DLK ile oluşan korneal doku hasarının tedavisinde ciddi katkısı olabilecektir. ${ }^{38}$ 
Postoperatif 1. gün kontrolü ile periferik korneadaki aşırı inflamasyon ciddiye alınmalı ve hemen en uygun tedavi protokolü uygulanmalıdır. Postoperatif 5. günden sonra temiz bir kornea DLK riskinin iyice azaldığını gösterir. DLK gelişiminde refraktif korneal lazer operasyonlarından önce, cerrahi sırasında ve sonrasında alınacak çeşitli önlemler en az tedavi kadar önemlidir.

\section{Sonuç}

DLK'e karşı, predispozan endojen, ekzojen ve cerrahi faktörlerin eliminasyonu için hastaya, ameliyat ortamına ve cerrahiye yönelik alınacak önlemler ve dikkat edilecek hususlara da mutlaka dikkat edilmelidir.

Refraktif lazer cerrahisi konusundaki kişisel deneyimler, postoperatif DLK'dan korunmak için alınabilecek bazı önlemler olduğunu göstermektedir. Refraksiyon cerrahisi sürecinde;

- Pudrasız steril eldiven kullanması,

- Cerrahi alanin mutlaka steril bir şekilde kurulanması,

- Flep ara yüzeyinde ya da stromal yatakta kurulama dahil hiçbir şekilde sponge kullanılmaması,

- Flep oluşturuken yüksek lazer enerjisinden kaçınılması,

- Lazer sonrası flep kapatıldıktan sonra cerrahi sınırdaki birikmiş sıvının alınması,

- Lazere başlamadan tüm hücresel ve kimyasal debrislerin temizlenmesi (çapak, aşırı seklesyon, makyaj vb),

- Lazer odasının hepa filitlereninin temiz ve bakımlı olması,

- Femto saniye flep poztop reposizyonu ve iyileşmesi için gereksiz yere kontak lens kullanmaması,

- Croslinging girişiminden sonra korneal yatağın titizlikle yıkanması,

- Refraktif lazer cerrahisinden sonra ilk günde kortikosteoritli damla başlanması,
- Hastanın postoperatif birinci günde değil ikinci günde kontrol muayenesine çağrılması

DLK gelişimine neden olacak faktörlerin ortadan kaldırılması için önerilebilir. Ancak bu önlemlerin ne kadar etkin olduğu, kontrollü deneysel çalışmalar ile desteklenmelidir.

\section{Kaynaklar}

1. Stulting RD, Randleman JB, Couser JM, Thompson KP. The epidemiology of diffuse lamellar keratitis. Cornea 2004;23(7):680-8.

2. Smith RJ, Maloney RK, Diffuse lamellar keratitis: A new syndrome in lamellar refractive surgery. Ophthalmology 1998;105(9):1721-6.

3. Yildirim Y, Olcucu O, Alagoz C, et al. Visual and refractive outcomes of photorefractive keratectomy and small incision lenticule extraction (SMILE) for myopia. J Refract Surg 2016;32(9):60410.

4. Buxey K. Delayed onset diffuse lamellar keratitis following enhancement LASIK surgery. Clin Exp Optom 2004;87(2):102-6.

5. Kohnen T, Schwarz L, Remy M, Shajari M. Short-term complications of femtosecond laser-assisted laser in situ keratomileusis cuts: Review of 1210 consecutive cases. J Cataract Refract Surg 2016;42(12):1797-1803.

6. Moshirfar M, Murri MS, Shah TJ, Linn SH, Ronquillo Y, Birdsong OC, Hoopes PC. Initial single-site surgical experience with SMILE: A comparison of results to FDA SMILE, and the earliest and latest generation of LASIK. Ophthalmol Ther 2018;7(2):316-22.

7. Schallhorn SC, Amesbury EC, Tanzer DJ. Avoidance, recognition, and management of LASIK complications. Am J Ophthalmol 2006;141(4):733-9. 
8. Choe CH, Guss C, Musch DC, Niziol LM, Shtein RM. Incidence of diffuse lamellar keratitis after LASIK with $15 \mathrm{KHz}, 30$ $\mathrm{KHz}$, and $60 \mathrm{KHz}$ femtosecond laser flap creation.J Cataract Refract Surg 2010;36(11):1912-8.

9. RP Steck, GA Justin, TA Soeken, GL Legault. Diffuse lamellar keratitis 14 years after laser in situ keratomileusis induced by an eyelash in the flap interface. JCRS Case Rep 2018;6(4):6970

10. Moilanen JA, Holopainen JM, Helinto M, Vesaluoma MH, Tervo TM. Keratocyte activation and inflammation in diffuse lamellar keratitis after formation of an epithelial defect. J Cataract Refract Surg 2004;30(2):341-9.

11. Yuhan KR, Nguyen L, Wachler BS. Role of instrument cleaning and maintenance in the development of diffuse lamellar keratitis. Ophthalmology 2002;109(2):400-3.

12. Rosman M, Chua WH, Tseng PSF, Wee TL, Chan WK. Diffuse lamellar keratitis after laser in situ keratomileusis associated with surgical marker pens. $J$ Cataract Refract Surg 2008;34(6):9749.

13. Noda-Tsuruya T, Toda I, Asano-Kato N, Hori-Komai Y, Fukumoto T, Tsubota K. Risk factors for development of diffuse lamellar keratitis after laser in situ keratomileusis. $J$ Refract Surg 2004;20(1):72-5.

14. Lira LH, Hirai FE, Oliveira M, Portellinha W, Nakano EM. Use of the Ishikawa diagram in a case-control analysis to assess the causes of a diffuse lamellar keratitis outbreak. Arq Bras Oftalmol 2017;80(5):281-4.

15. Castoro CJ. Causes of diffuse lamellar keratitis. Ophthalmology 2003;110(5):873-4.

16. Yu CQ, Manche EE. Comparison of 2 femtosecond lasers for flap creation in myopic laser in situ keratomileusis: one year results. J Cataract Refract Surg 2015;41(4):740-8.

17. Ganesh S, Brar S, Arra RR. Refractive lenticule extraction small incision lenticule extraction: a new refractive surgery paradigm. Indian J Ophthalmol 2018;66(1):10-9.

18. Johnson JD, Harissi-Dagher M, Pineda R, Yoo S, Azar DT. Diffuse lamellar keratitis: incidence, associations, outcomes, and a new classification system. J Cataract Refract Surg 2001;27(10):1560-6.

19. Linebarger EJ, Hardten DR, Lindstrom RL. Diffuse lamellar keratitis: diagnosis and management. J Cataract Refract Surg 2000;26(7):1072-7.

20. Reinstein DZ, Stuart AJ, Vida RS, Archer TJ, Carp GI. Incidence and outcomes of sterile multifocal inflammatory keratitis and Diffuse Lamellar Keratitis after SMILE. J Refract Surg 2018;34(11):751-9.

21. Murueta-Goyena A, Cañadas P. Visual outcomes and management after corneal refractive surgery: A review. $J$ Optom 2018;11(2):121-9.

22. Dawson DG, Schmack I, Holley GP, Waring GO 3rd, Grossniklaus HE, Edelhauser HF. Interface fluid syndrome in human eye bank corneas after LASIK: causes and pathogenesis. Ophtalmology 2007;114(10):1848-59.

23. Gritz DC. LASIK interface keratitis: epidemiology, diagnosis and care. Curr Opin Ophthalmol 2011;22(4):251-5.

24. Ambrosio R Jr, Periman LM, Netto MV, Wilson SE. Bilateral marginal sterile infiltrates and diffuse lamellar keratitis after laser in situ keratomileusis. J Refract Surg 2003;19(2):154-8.

25. Alió JL, Azar DT. Management of complications in refractive surgery. 2 nd ed, Springer: Cham, Switzerland, 
2018:61-7.

26. Randleman JB, Rupa DS. LASIK interface complications: etiology, management, and outcomes.J Refract Surg 2012;28(8):575-86.

27. Jeng BH, Stewart JM, McLeod SD, Hwang DG. Relapsing diffuse Lamellar Keratitis after Laser in situ keratomileusis associated with Recurrent Erosion Syndrome. Arch Ophthalmol 2004;122(3):396-8.

28. Jarade E, Slim E, Antoun J, Khzam RA. Treatment of grade IV diffuse lamellar keratitis with oral doxycycline and topical $10 \%$ sodium citrate. Can J Ophthalmol 2016;51(6):e178-84.

29. Mimouni M, Vainer I, Assad N, Nemet A, Sela T, Munzer G, Kaiserman I. Incidence, indications, and outcomes of eyes needing early flap lifting after LASIK. Cornea 2018;37(9):1118-23.

30. Shah MN, Misra M, Wihelmus KR, Koch DD. Diffuse lamellar keratitis associated with epithelial defects after laser in situ keratomileusis. J Cataract Refract Surg 2000;26(9):1312-8.

31. Oliveira RF, Stonecipher KG, Ignacio TS, Ghanem RC, Ghanem CV, de la Cruz J, Azar DT. Complications Related to Femtosecond Laser-Assisted LASIK. Management of complications in refractive surgery. 2nd ed, Springer: Cham, Switzerland, 2018:227-41.

32. Chuckpaiwong V, Nithithanaphat C, Jongkhajornpong $\mathrm{P}$, Lekhanont $\mathrm{K}$. Epithelial basement membrane dystrophy after femtosecond laserassisted laser in situ keratomileusis. Can J Ophthalmol 2018;53(2):44-6.

33. Holland S, Lin DTC, Hogden J. Topography-Guided Excimer Laser Surgery: Indications and Techniques. In: Febbraro JL, Khan H, Koch D, eds. Surgical Correction of Astigmatism. Springer, Cham: 2018:143-54.

34. Buhren J, Baumeister M, Cichocki M,
Kohnen T. Confocal microscopic characteristics of stage 1 to 4 diffuse lamellar keratitis after laser in situ keratomileusis. J Cataract Refract Surg 2002;28(8):1390-9.

35. Zhao J, He L, Yao P, Shen Y, Zhou Z, Miao $\mathrm{H}$, Wang X, Zhou X. Diffuse lamellar keratitis after small-incision lenticule extraction. J Cataract Refract Surg 2015;41(2):400-7.

36. Buratto L, Brint SF. Custom LASIK surgical techniques and complications. Thorofare: Slack. 2003:p.214-9, 242-6.

37. Balestrazzi A, Balestrazzi A, Giannico MI, Michieletto P, Balestrazzi E. Diagnosis, clinical trend, and treatment of diffuse lamellar keratitis after femtosecond laser-assisted in situ keratomileusis: A case report. Case Rep Ophthalmol 2018;9(3):457-64.

38. Shojaati G, Khandaker I, Sylakowski K, Funderburgh ML, Du Y, Funderburgh JL. Compressed collagen enhances stem cell therapy for corneal scarring. Stem Cells Transl Med 2018;7(6):487-94. 